Abstract for submission to MRS 1998 Spring Meeting, April 13-17, San Francisco, CA

Symposium F: Wide-Bandgap Semiconductors for High Power, High Frequency and High Temperature

\title{
NON-MICROPIPE DISLOCATIONS IN 4H-SiC DEVICES: ELECTRICAL PROPERTIES AND DEVICE TECHNOLOGY IMPLICATIONS
}

Philip G. Neudeck. NASA Lewis Research Center, Cleveland, OH; Wei Huang, Michael Dudley, State University of New York at Stony Brook, NY; Christian Fazi, U.S. Army Research Laboratory, Adelphi, MD.

It is well-known that $\mathrm{SiC}$ wafer quality deficiencies are delaying the realization of outstandingly superior $4 \mathrm{H}-\mathrm{SiC}$ power electronics. While efforts to date have centered on eradicating micropipes (i.e., hollow core super-screw dislocations with Burgers vectors $\geq 2 \mathrm{c}$ ), $4 \mathrm{H}-\mathrm{SiC}$ wafers and epilayers also contain elementary screw dislocations (i.e., Burgers vector $=1 \mathrm{c}$ with no hollow core) in densities on the order of thousands per $\mathrm{cm}^{2}$, nearly 100 -fold micropipe densities. While not nearly as detrimental to $\mathrm{SiC}$ device performance as micropipes, it has recently been demonstrated that elementary screw dislocations somewhat degrade the reverse leakage and breakdown properties of $4 \mathrm{H}-\mathrm{SiC} \mathrm{p}^{+} \mathrm{n}$ diodes. Diodes containing elementary screw dislocations exhibited a $5 \%$ to $35 \%$ reduction in breakdown voltage, higher pre-breakdown reverse leakage current, softer reverse breakdown I-V knee, and microplasmic breakdown current filaments that were non-catastrophic as measured under high series resistance biasing. This paper details continuing experimental and theoretical investigations into the electrical properties of $4 \mathrm{H}-\mathrm{SiC}$ elementary screw dislocations. The nonuniform breakdown behavior of $4 \mathrm{H}-\mathrm{SiC} \mathrm{p}^{+} \mathbf{n}$ junctions containing elementary screw dislocations exhibits interesting physical parallels with nonuniform breakdown phenomena previously observed in other semiconductor materials. Based upon experimentally observed dislocation-assisted breakdown, a re-assessment of wellknown physical models relating power device reliability to junction breakdown has been undertaken for $4 \mathrm{H}-\mathrm{SiC}$. The potential impact of these elementary screw dislocation defects on the performance and reliability of various $4 \mathrm{H}-\mathrm{SiC}$ device technologies being developed for high-power applications will be discussed. 


\title{
NON-MICROPIPE DISLOCATIONS IN 4H-SiC DEVICES: ELECTRICAL PROPERTIES AND DEVICE TECHNOLOGY IMPLICATIONS
}

\author{
P. G. NEUDECK*, W. HUANG**, M. DUDLEY**, AND C. FAZI*** \\ *NASA Lewis Research Center, M.S. 77-1, 21000 Brookpark Rd., Cleveland, OH 44135 \\ **Dept. of Materials Science \& Engineering, SUNY, Stony Brook, NY 11794 \\ ***U.S. Army Research Laboratory, Adelphi, MD 20783
}

\section{ABSTRACT}

It is well-known that $\mathrm{SiC}$ wafer quality deficiencies are delaying the realization of outstandingly superior $4 \mathrm{H}-\mathrm{SiC}$ power electronics. While efforts to date have centered on eradicating micropipes (i.e., hollow core super-screw dislocations with Burgers vectors $>2 \mathrm{c}$ ), 4H-SiC wafers and epilayers also contain elementary screw dislocations (i.e., Burgers vector $=1 \mathrm{c}$ with no hollow core) in densities on the order of thousands per $\mathrm{cm}^{2}$, nearly 100 -fold micropipe densities. While not nearly as detrimental to $\mathrm{SiC}$ device performance as micropipes, it has been previously shown that diodes containing elementary screw dislocations exhibit a $5 \%$ to $35 \%$ reduction in breakdown voltage, higher pre-breakdown reverse leakage current, softer reverse breakdown I-V knee, and concentrated microplasmic breakdown current filaments when measured under DC testing conditions. This paper details the impact of elementary screw dislocations on the experimentally observed reverse-breakdown pulse-failure characteristics of low-voltage $(<250 \mathrm{~V})$ small-area $(<5$ $\times 10^{-4} \mathrm{~cm}^{2}$ ) $4 \mathrm{H}-\mathrm{SiC} \mathrm{p}^{+} \mathrm{n}$ diodes. The presence of elementary screw dislocations did not significantly affect the failure properties of these diodes when subjected to non-adiabatic breakdown-bias pulsewidths ranging from $0.1 \mu \mathrm{s}$ to $20 \mu \mathrm{s}$ in duration. Diodes with and without elementary screw dislocations exhibited positive temperature coefficient of breakdown voltage and high junction failure power densities well above the failure power densities exhibited by highly reliable silicon power rectifiers. This preliminary result, based on measurements from one wafer of $\mathrm{SiC}$ diodes, suggests that highly reliable low-voltage $\mathrm{SiC}$ rectifiers may be attainable despite the presence of elementary screw dislocations.

\section{INTRODUCTION}

It is widely recognized that material quality deficiencies are the primary reason why SiC highpower devices cannot be realized at present. While small-current, small-area high-voltage (1-5 kV) $\mathrm{SiC}$ devices are being prototyped and tested, the high densities of crystallographic defects in $\mathrm{SiC}$ wafers prohibits the attainment of $\mathrm{SiC}$ devices with very high operating currents $(>50 \mathrm{~A})$ that are commonly obtainable in silicon-based high-power electronics $[1,2]$. Micropipe defects are clearly very detrimental to electrical device performance, as these defects cause premature breakdown point-failures in $\mathrm{SiC}$ high-field devices fabricated in $4 \mathrm{H}$ - and $6 \mathrm{H}-\mathrm{SiC}$ c-axis crystals with and without epilayers [2]. Commercial $4 \mathrm{H}$ - and $6 \mathrm{H}-\mathrm{SiC}$ wafers and epilayers also contain elementary screw dislocations (i.e., Burgers vector $=1 \mathrm{c}$ with no hollow core) in densities on the order of thousands per $\mathrm{cm}^{2}$, nearly 100-fold micropipe densities [3-6]. Because of the non-terminating behavior of screw dislocations, both hollow-core (micropipes) and non-hollow-core (elementary) screw dislocations and associated crystal lattice stresses are replicated in subsequently grown $\mathrm{SiC}$ epilayers $[7,8]$.

The electrical impact of elementary screw dislocation defects on $\mathrm{SiC}$ device performance has largely been overlooked while attention has focused on eradicating $\mathrm{SiC}$ micropipes. However, as $\mathrm{SiC}$ micropipe densities fall below 1 per $\mathrm{cm}^{2}$ in the best reported wafers [9], the operational effects of elementary screw dislocations must now be considered. While not nearly as detrimental to SiC device performance as micropipes, it has recently been demonstrated that elementary screw dislocations somewhat degrade the reverse leakage and breakdown properties of $4 \mathrm{H}-\mathrm{SiC} \mathrm{p}^{+} \mathrm{n}$ diodes [10]. Diodes containing elementary screw dislocations exhibited a $5 \%$ to $35 \%$ reduction in breakdown voltage, higher pre-breakdown reverse leakage current, softer reverse breakdown I-V knee, and highly localized microplasmic breakdown current filaments.

Localized breakdowns and high-current filaments at junction hotspots are undesirable in silicon-based solid-state power devices. In operational practice, silicon power devices that 

uniformly distribute breakdown current over the entire junction area exhibit much greater reliability
than silicon devices that manifest localized breakdown behavior. This is because silicon devices
that avoid localized junction breakdown exhibit larger Safe Operating Areas (SOA's) and
better withstand repeated fast-switching tresses and high-power systems [11-14] Powitching stresses and transient standard behavior in silicon. Positive temperature coefficient of current flow is distributed uniform devices free of crystal dislocation defor voltage (PTCBV), a filaments. This enables silicon power throughout a device, instead of concects, helps insure that when subjected to transient breakdown rectifiers to exhibit a high energy to therated at high-current are simultaneously large in the device or switching bias conditions in to thermal junction failure reliability increases with increasing sem. It is generally accepted that which voltage and current systems. to be considered reliable for use in high-powy power devices can become feasible for widespread incorpust high-power day dislocation-free silicon power devices. Therefore, SiC power devices must deristics as present-
equal, if not superior, SOA's and immunity to devices. Since all appreciable current $(>1$ ity to switching and overvoltage stresses as demotre at least elementary screw dislocations, it is $(>1 \mathrm{~A})$ SiC power devices are virtually guaran silicon power fail characteristics of $\mathrm{SiC}$ diodes with paper quantitatively compares (to first elementary screw dislocations. The slown and energy-tocharacteristics of $4 \mathrm{H}-\mathrm{SiC} \mathrm{p}^{+} \mathrm{n}$ junction known failure SILICON AND SILICON CARBIDE JUNCTO diodes.

\section{SILICON AND SILICON CARBIDE JUNCTION FAILURE THEORY}

voltage pulses that momenting diode junction failure characteristics is to subject the device to highbreakdown current is drawn at high applied voltage, a large reverse breakdown voltage. As high until a critical junction heats up the device. Pulses of increasing amplitur power is dissipated at the damaged. For short pulse durations rature $T_{m}$ is reached, at which point the der duration are applied exclusively from the active device junction $0.1 \mu \mathrm{s}$ and $20 \mu \mathrm{s}$ in length, heat flow unrecoverably the substrate to the package is essentially ne bulk semiconductor wafer substrate; heat flow almost derived a general first-order appreximally negligible on this timescale. Wunsch starting temperature of $T_{i}$ :

$$
P_{D}=\sqrt{\pi k \rho C_{p}}\left[T_{m}-T_{i}\right] t^{-1 / 2} k W / \mathrm{cm}^{2}
$$

where $x$ is the thermal conductivity $(W / \mathrm{cm}-\mathrm{K}), \rho$ is the density $(\mathrm{g} / \mathrm{cm})$ and of the semiconductor $(\mathrm{J} / \mathrm{gm}-\mathrm{K})$. One choice for $T_{\mathrm{m}}$ is the temperature and $C_{\mathrm{p}}$ is the specific heat degradation can also doping leading to second $\mathrm{T}_{\mathrm{m}}$ is the temperature at which intrinsic carriers general first-order calculations temperature a device can withstand without diconductor contact curve calculated by Wunsch to the semiconductor Debye temperanumetion doping and contact $\kappa=0.526 \mathrm{~W} / \mathrm{cm}-\mathrm{K}, \mathrm{T}_{i}=298 \mathrm{~K}$ Bell [15] for silicon using $\rho=2.33 \mathrm{~g}_{\mathrm{D} \cdot}$. The theoretical $\mathrm{P}_{\mathrm{D}}$ vs. $\mathrm{t}$

$$
P_{D}=1109[\mathrm{t}(\mu \mathrm{s})]^{-1 / 2} \mathrm{~kW} / \mathrm{cm}^{2}
$$

wide variety of found that (1) reasonably approximates $P_{D}$ vs. $t$ curve they observed for silicon rectifier diodes actually followed the reberved best fit to the 


$$
P_{D}=560[t(\mu s)]^{-1 / 2} \mathrm{~kW} / \mathrm{cm}^{2}
$$

which lies somewhat below the theoretical calculation (2). Silicon experimental studies also indicate that pulse shape does not signifucan as a good approximation when diode voltage and/or

so that average power density may be used are non-constant over the pulse duration [14].
current waveforms are the effective power density,

If current flow is focused thranction area instead of the hotspot junction area, will decrease which is normalized the

flows through only $10 \%$
shifts downward to [15]:

$P_{D}=110.9[t(\mu s)]^{-12} \mathrm{~kW} / \mathrm{cm}^{2} \quad$ [Silicon $10 \%$ Hotspot Theoretical\}

Similar to the above first-order calculations for silicon rectifiers, theoretical $P_{D}$ vs. $t$ failure characteristics of $4 \mathrm{H}-\mathrm{SiC}$ rectifiers can be estimaly functions of temperature, their temperature specific heat and thermal conductivity an in these first-order calculations. Furthermore, there is dependence has not been taken into account in thermal properties that have been reported in the scientific inconsistency between the few SIC thest-case" and "worst-case" combinations of thermal conductivity literature. Nevertheless, basic "best-cas roughly estimate upper and lower theoretical lims on the and specific heat can be calculated that might be observed in defect-free $4 \mathrm{H}-\mathrm{SiC}$ junctions. For both junction failure power densit $T_{1}=298 \mathrm{~K}$, and $T_{m}=T_{D}=1120 \mathrm{~K}$ [16] were used. The described by calculations, $\rho=3.2 \mathrm{~g} J / \mathrm{gm}-\mathrm{K}$ at $300 \mathrm{~K}$ is calculated using the simple $\mathrm{W} / \mathrm{cm}-\mathrm{K}$ is chosen based on specific heat $C_{p}=0.3$ worst-case $4 \mathrm{H}-\mathrm{SiC}$ thermal conductivity $K=$ in

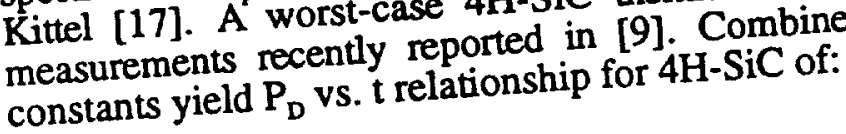

$$
P_{D}=2014[t(\mu s)]^{-1 / 2} \mathrm{~kW} / \mathrm{cm}^{2}
$$

The best-case thermal conductivity $K=4.9 \mathrm{~W} / \mathrm{cm}-\mathrm{K}$ was chosen from Slack's measurements of $6 \mathrm{H}-\mathrm{SiC}$ at $300 \mathrm{~K}$ [18]. The work of Zyweitz et. al. [16] suggests that the specing $600 \mathrm{~K}$. Using these does not increase much beyond $C_{p}=1$.

thermal parameters, the best-case first-order estimation of

$$
P_{D}=5755[\mathrm{t}(\mu \mathrm{s})]^{-1 / 2} \mathrm{~kW} / \mathrm{cm}^{2}
$$

Theoretical relations (2) through (6) are plotted in Figure 2 for reference to experimental data presented in the following section.

\section{EXPERIMENT} EXPERIMENT
Epitaxial mesa-isolated 4H-SiC $\mathrm{p}^{+} \mathrm{n}$ junction diodes (n-doping between $2.5 \times 10^{17}$ to $1.5 \times 10^{18}$
$\mathrm{~cm}^{-3}$ ) were fabricated on commercial $4 \mathrm{H}-\mathrm{SiC}$ substrates as previously described in [10]. Nickel
(1) annealed at $1000^{\circ} \mathrm{C}$ for 5 minutes in an argon tube furnace served by liftoff provided good ohmic unannealed $300 \AA \mathrm{Al} / 100 \mathrm{~A}$.

The presence or absence of screw dislocations in inonstrated in [10]. A total of 17 circular determined by examination of reverse I-V properties $250 \mu \mathrm{m}$ in diameter were pulse-tested to failure diodes varying in size from $100 \mu \mathrm{m}$ no elementary screw dislocations. Devices were pulse touls pulse in this work, 6 of which contions on a probing station equipped with [19] was employed to apply on-wafer in near-dark $0.5 \mu \mathrm{s}$, the charge-line circuit describedient response. Longer bias pulses durations of less than $0.5 \mu \mathrm{s}$, the charge-line cirent $I_{D}(t)$ transient response. Lobjected to manually
pulses and measure device voltage $V_{p}(t)$ and current were supplied by a Velonex 

triggered single-shot pulses of increasing pulse amplitudes and/or widths until device failure
occurred. Between pulses, device $\mathrm{I}-\mathrm{V}$ was checked for degradation using a standard $60 \mathrm{~Hz}$ curve-
tracer. Device failure was observed by sudden changes in the $\mathrm{I}$. in the curve-tracer measured $I-V$, furden changes in the $I_{D}(t)$ and $V_{D}(t)$ response, degradation probe station microscope. Devices were somsical changes in device appearance observed with the reduce the possibility of edge-related sumetimes tested immersed in Fluorinert FC-77 [20] to

Post-failure optical microscopic exarface flashover [21], while others were tested in air.

A few devices exhibited clear evidence of devices were totally obliterated similar to surface flashover failure near the mesa periphery. A few bulk junction failure was seen in the majat is depicted in [22]. However, strong evidence of damage was confined to near-central majority of diodes tested, as physical contact and mesa

often away from where the probe tip contacted the diode.
Figure 1 shows $Y$. diameter device that contained $I_{D}(t)$ traces of a typically observed device failure on a $200 \mu \mathrm{m}$ first $0.05 \mu \mathrm{s}$ of the pulse, the device exhibits and was tested immersed in Fluorinert. For the voltage (NTCBV) behavior, as $I_{D}(t)$ shows an initiane temperature coefficient of breakdown However, the trend reverses to PTCBV behavior increase while $V_{D}(t)$ shows an initial decrease. device self heats beyond $0.2 \mu$ s into the pulse. Thus, as $I_{D}(t)$ decreases and $V_{D}(t)$ increases as the that $4 \mathrm{H}-\mathrm{SiC} \mathrm{p}^{+} \mathrm{n}$ junction diodes containing elementary screw dislocations can exhibit work is
behavior.

At $t=0.44 \mu \mathrm{s}$, the with voltage collapse prior to the falling edgeed by the onset of a sharp current increase coupled immediately following the pulse confirmed the the $0.5 \mu \mathrm{s}$ bias pulse. Curve-tracer characterization Figure 1 pulse. An average device power density $P$. failed to a resistive short-circuit during the over the pulse prior to failure and dividing by the total junction ated by averaging $P(t)=V_{D}(t) I_{D}(t)$ average power density $P_{D}$ of $4.17 \mathrm{MW} / \mathrm{cm}^{2}$ over a period the device withstood an the experimental data points plotted in Figure a period of $0.44 \mu \mathrm{s}$ in Figure 1, which is one of physical damage in the near-central device 2 . Post-failure analysis of this device indicated failure.

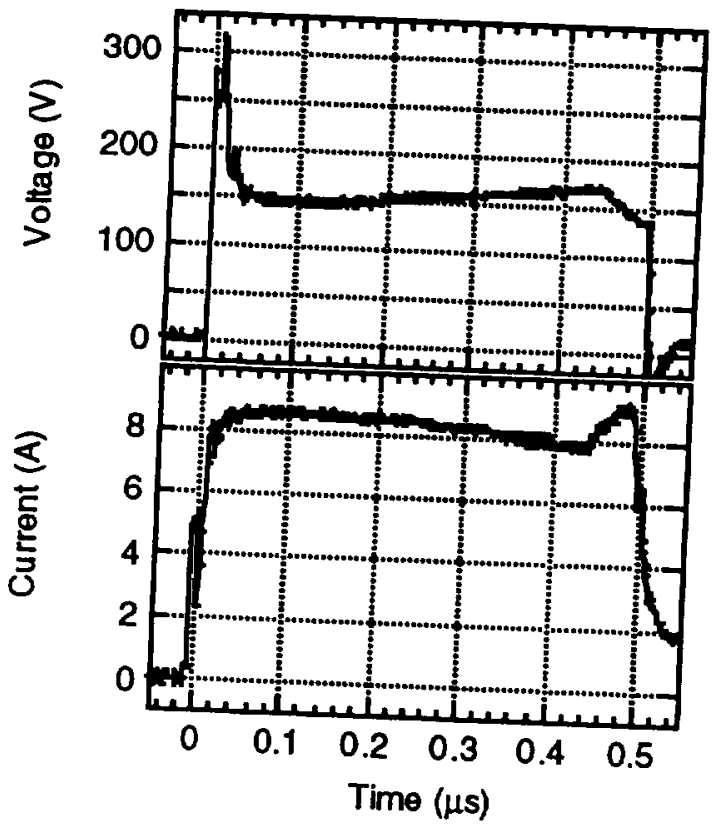

Figure 1: Diode voltage $V_{p}(t)$ and current $I_{D}(t)$ transients recording the failure of a $200 \mu \mathrm{m}$ diameter $4 \mathrm{H}-\mathrm{SiC} \mathrm{p}^{+} \mathrm{n}$ diode under pulse-breakdown testing. The diode fails at $0.44 \mu \mathrm{s}$, prior to the falling edge of the $0.5 \mu \mathrm{s}$ bias pulse.

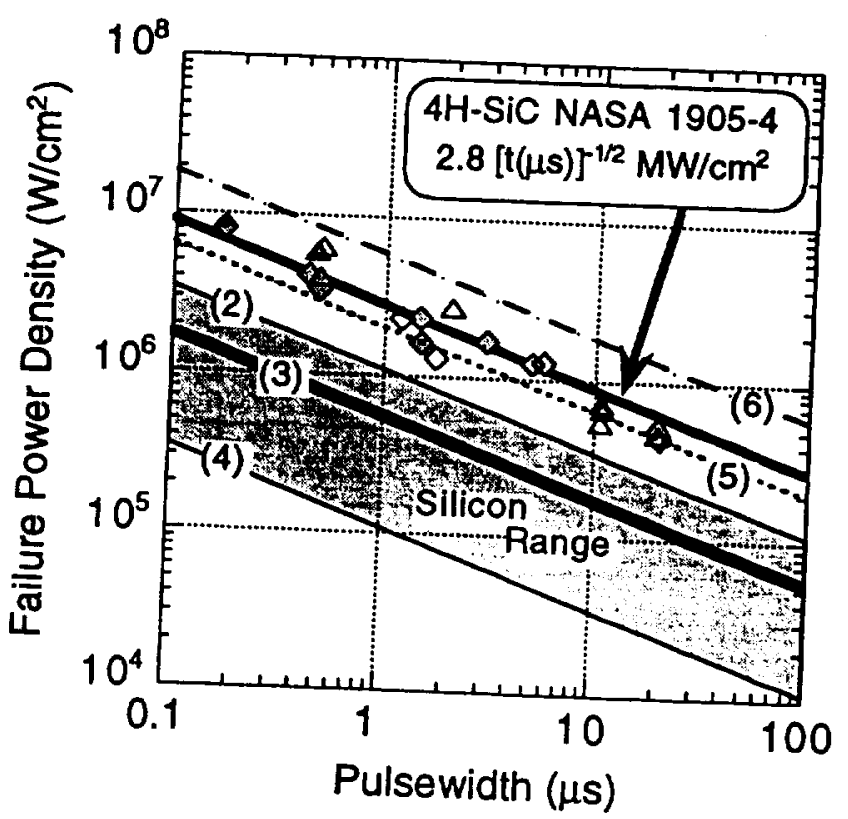

Figure 2: Average power density $P_{D}$ vs. pulse bias duration $t$ for device reverse breakdown failure. Experimental data points for NASA 4H-SiC $\mathrm{p}^{+} \mathrm{n}$ diode sample 1905-4 are plotted along with and (5) \& (6) for $4 \mathrm{H}-\mathrm{SiC}$ discussed in the main text 
Figure 2 shows all experimentally $P_{D}$ vs. $t$ failure data points collected in this study on devices whose DC-measured breakdown voltages ranged from $70 \mathrm{~V}$ to $220 \mathrm{~V}$ due to n-layer doping variation across the wafer. Diamond symbols on the plot represent devices that clearly exhibited bulk failure where exact failure times and power densities could be directly inferred from the $V_{D}(t)$ and $I_{D}(t)$ traces. Triangles represent data points that were collected from pulses in which a diode did not fail (failure occurred during a subsequent pulse), or from pulses where the diode failure occurred at the edge of a device mesa presumably due to surface flashover. Devices that contained
no screw dislocations are denoted by open symbols, while filled symbols represent data collected from devices that contained at least one screw dislocation.

The experimentally observed failure data points plotted in Figure 2 are consistent with the $t^{-1 / 2}$ behavior predicted by Relation (1). The fit to the experimental data:

$$
P_{D}=2800[\mathrm{t}(\mu \mathrm{s})]^{-1 / 2} \mathrm{~kW} / \mathrm{cm}^{2} \quad\{4 \mathrm{H}-\mathrm{SiC} \text { Experimental }\}
$$

falls between the theoretical $4 \mathrm{H}-\mathrm{SiC}$ limits approximated in (5) and (6). Thus, these $4 \mathrm{H}-\mathrm{SiC}$ parts can withstand pulse breakdown power densities approximately 5 times the power density that silicon diodes typically withstand before junction failure is reached. It is important to note that this preliminary data indicates that the presence or absence of elementary screw dislocations from a preliminary data indicates that the presence or absence of eleme fiode low-voltage $4 \mathrm{H}-\mathrm{SiC}$ diodes.
diode had no significant impact on the reverse failure energy of these low
Devices with and without screw dislocations exhibited comparable failure power densities to within the range of experimental scatter shown in Figure 2.

\section{CONCLUSION}

The presence of elementary screw dislocations did not significantly affect the failure properties of low-voltage $(<250 \mathrm{~V}) 4 \mathrm{H}-\mathrm{SiC} \mathrm{p}^{+} \mathrm{n}$ junction diodes when subjected to non-adiabatic breakdownbias pulses. Diodes with and without elementary screw dislocations exhibited positive temperature coefficient of breakdown voltage and high junction failure power densities well above the failure coefficient of breakdown voltage and high junction failure power
power densities exhibited by highly reliable silicon power rectifiers. This preliminary result, based
on measurements from one wafer of $4 \mathrm{H}-\mathrm{SiC} \mathrm{p}^{+} \mathrm{n}$ diodes, suggests that highly reliable low-voltage $\mathrm{SiC}$ rectifiers may be attainable in diodes that contain elementary screw dislocations. However, further studies are needed to ascertain the impact of screw dislocations on the failure properties of $4 \mathrm{H}-$ and $6 \mathrm{H}-\mathrm{SiC}$ Schottky rectifiers, high-voltage $(>1 \mathrm{kV}) \mathrm{p}^{+} \mathrm{n}$ rectifiers, and other SiC device structures with significant bipolar gain such as thyristors and IGBT's.

\section{ACKNOWLEDGMENTS}

The authors would like to gratefully acknowledge the assistance of D.J. Larkin, J. A. Powell, C. Salupo, G. Beheim, L. Keys, A. Trunek, J. Heisler of NASA Lewis Research Center. Work at NASA Lewis was carried out under joint funding from NASA Lewis Research Center and Defense Advanced Research Projects Agency (DARPA) Order \#D149 (monitored by J. Alexander) and Order \#E111/3 (monitored by E. Brown).

\section{REFERENCES}

1. P. G. Neudeck, J. Electron. Mater. 24 (4), 283-288 (1995).

2. P. G. Neudeck and J. A. Powell, IEEE Electron Device Lett. 15 (2), 63-65 (1994).

3. M. Dudley, S. Wang, W. Huang, C. H. Carter, Jr., and C. Fazi, J. Phys. D 28 A63-A68 (1995).

4. S. Wang, M. Dudley, C. H. Carter, Jr., V. F. Tsvetkov, and C. Fazi in Applications of Synchrotron Radiation Techniques to Materials Science, edited by L. Terminello, N. Shinn, G. Ice, K. D'Amico, and D. Perry (Mater. Res. Soc. Proc. 375, Pittsburgh, PA 1995), pp. 281-286. 
5. W. Si, M. Dudley, R. Glass, V. Tsvetkov, and C. H. Carter, Jr., J. Electron. Mater. 26 (3),
128-133 (1997).

6. W. Si and M. Dudley in Silicon Carbide. II-Nitrides, and Related Materials, edited by G. Tech Publications, Switzerland 1998), pp. 429-432. Bandgap Semiconductors, edited by C. H. Carter, Jr., G. Gildenblat, S. Nakamura, and R. J.

8. J. A Powell D.

Related Materials, edited by M. G. Spencer. W. Yang, and P. Pirouz in Silicen Carbide and Kaplan, and M. Rahman (Institute of Physics Conference Series 137, Bristol, UK 1994), R.
161-164. 9. V. F. Tsvetkov, R. C. Glass, D. Henshall, D. A. Asbury, and C. H. Carter, Jr. in Silicon
Carbide. III-Nitrides, and Related Materials, edited by G. Pensl, H. Morkoc, B. Monemar,
and E. Janzen (Materials Science Forum 264-268, Trans Tech Publications, Switzerland
1998), pp. 3-8. Res. Soc. Proc. 483, Warrandale, PA, 1998).

11. S. M. Sze, Physics of Semiconductor Devices, 2nd ed., Wiley-Interscience, New York, 1981,
pp. 169-175.

12. B. J. Baliga, Modern Power Devices, Wiley-Interscience, New York, 1987, pp. 314-318.

13. L. W. Ricketts, J. E. Bridges, and J. Miletta, EMP Radiation and Protective Techniques,
Wilo, 1976 .

14. R. N. Ghose, EMP Environment and System Hardness Design, D. White Consultants,
Gainesville, VA, 1984, pp. 4.1-4.31.

15. D. C. Wunsch and R. R. Bell, IEEE Trans. Nucl. Sci. 15 (6), 244-259 (1968).

16. A. Zywietz, K. Karch, and F. Bechstedt, Physical Review B 54 (3), 1791-1798 (1996).

17. C. Kittel, Introduction to Solid State Physics, 6th ed., Wiley, New York, 1986, pp. 99-122.

18. G. A. Slack, J. Appl. Phys. 35 (12), 3460 (1964).

19. P. G. Neudeck and C. Fazi, J. Appl. Phys. 80 (2), 1219-1225 (1996).

20. Fluorinert ${ }^{\mathrm{TM}}, 3 \mathrm{M}$ Company, St. Paul, MN 55144.

21. G. Gradinaru, V. P. Madangarli, and T. S. Sudarshan, IEEE Trans. Electron Devices 41 (7),
1233-1238 (1994).

22. P. G. Neudeck, D. J. Larkin, J. A. Powell, L. G. Matus, and C. S. Salupo, Appl. Phys. Lett.
64 (11), 1386-1388 (1994). 